\title{
CORRECTION
}

CrossMark \& click for updates

Cite this: Soft Matter, 2015, 11, 7066

DOI: $10.1039 / c 5 s m 90143 j$

www.rsc.org/softmatter

\section{Correction: Magnetically induced structural anisotropy in binary colloidal gels and its effect on diffusion and pressure driven permeability}

\author{
Christoffer Abrahamsson, ${ }^{* a b}$ Lars Nordstierna, ${ }^{a}$ Johan Bergenholtz, ${ }^{c}$ Annika Altskär ${ }^{d}$ \\ and Magnus Nydén ${ }^{\mathrm{e}}$
}

Correction for 'Magnetically induced structural anisotropy in binary colloidal gels and its effect on diffusion and pressure driven permeability' by Christoffer Abrahamsson et al., Soft Matter, 2014, 10. 4403-4412.

The authors regret to have overlooked the following mistakes in our original publication:

I. Page 4409 - says: "This decline yields, when used in eqn (4) with $S=0$, a $\phi_{\text {clay+bound }}$ corresponding to a bound water layer thickness of $1.4 \mathrm{~nm}$, which is in the same range previously reported for clay dispersions in the literature. ${ }^{42,45,46 \text {, }}$

Page 4409 - should be: "This decline yields, when used in eqn (4) with $S=-1 / 2$, a $\phi_{\text {claytbound }}$ corresponding to a bound water layer thickness of $1.4 \mathrm{~nm}$, which is in the same range previously reported for clay dispersions in the literature. ${ }^{42,45,46,}$

II. Page 4409 - eqn (5) says:

$$
\frac{D}{D_{0, \text { salt }}}=1+\frac{\alpha}{6} \phi_{\text {clay }}
$$

Page 4409 - should be:

$$
\frac{D_{\text {magnetic }}}{D_{\text {non-magnetic }}}=1+\frac{\alpha}{6} \phi_{\text {clay }}
$$

III. Page 4410 - says: "This results in $1.53 \pm 0.9$ plates in the average clay aggregate."

Page 4410 - should be: "This results in $1.53 \pm 0.09$ plates in the average clay aggregate."

The Royal Society of Chemistry apologises for these errors and any consequent inconvenience to authors and readers.

\footnotetext{
${ }^{a}$ Department of Chemical and Biological Engineering, Chalmers University of Technology, Kemivägen 10, 412 96, Gothenburg, Sweden. E-mail: abrahamc@chalmers.se

${ }^{b}$ SuMo Biomaterials, VINN Excellence Centre, Chalmers University of Technology, Gothenburg, 412 96, Sweden

${ }^{c}$ Department of Chemistry and Molecular Biology, University of Gothenburg, Kemivägen 10, 412 96, Gothenburg, Sweden

${ }^{d}$ Structure and Material Design, SIK - The Swedish Institute for Food and Biotechnology, SIK, PO Box 5401, 402 29 Gothenburg, Sweden

${ }^{e}$ Ian Wark Research Institute, University of South Australia, Mawson Lakes Campus, Mawson Lakes, SA, 5095, Australia
} 